\title{
AL 2024-T4 ALAŞIMININ NAKAJİMA TESTİ İLE ELDE EDİLEN ŞEKİLLENDİRME SINIR EĞRİSİNINN MİNİMUM MAJÖR DEĞERİNİN ÖTELENME NEDENLERİNİN İNCELENMESİ
}

\author{
Murat DÍLMEÇ*, Hüseyin Selçuk HALKACI ${ }^{* *}$, Fahrettin ÖZTÜRK ${ }^{* * * * * * * *}$ \\ * Makina Müh.Böl., Müh.-Mim. Fakültesi, Necmettin Erbakan Üniversitesi, 42090, Meram, Konya \\ ** Makina Müh. Böl., Mühendislik Fakültesi, Selçuk Üniversitesi, 42075, Selçuklu, Konya \\ *** Department of Mechanical Engineering, The Petroleum Institute, Abu Dhabi, U.A.E. \\ ***** Makina Müh. Böl., Mühendislik Fakültesi, Niğde Üniversitesi, 51245, Niğde \\ muratdilmec@konya.edu.tr, shalkaci@selcuk.edu.tr, fozturk@pi.ac.ae
}

(Geliş/Received: 06.11.2012; Kabul/Accepted: 29.05.2014)

\section{ÖZET}

Tipik bir şekillendirme sınır eğrisi (ŞSE)'nde, minimum majör birim şekil değiştirme değeri, minör birim şekil değiştirme değerinin sıfır olduğu $y$ ekseni üzerinde yer almaktadır. Birçok şekillendirme proseslerinde hasar bu bölgede meydana gelmektedir. Literatürde birçok çalışmada, ŞSE'lerde en düşük majör seviyesi hemen hemen $y$ ekseni üzerinde elde edilmiştir. Bu çalışmada ise Al 2024-T4 alaşımı için bu değer, $y$ ekseninden yaklaşık olarak 0,040 değerinde sağa doğru ötelenmiş olarak elde edilmiştir. Bu değer sac metal şekillendirme sonuçlarının değerlendirilmesinde önemli olabilmektedir. Bu çalışmada Al 2024-T4 sac metalin metalin minimum majör birim şekil değiştirme değerinin literatürden farklı olarak sağa ötelenmiş olarak elde edilmesinin nedenleri araştırılmıştır. Süzdürme çubuğu ve ısıl işlemin en fazla etki eden faktörler olduğu tespit edilmiştir. Ötelenmenin, süzdürme çubuğu kullanılarak yapılan testlerde oluşan ön BŞD’lerden ve T4 1sıl işlemi sonucunda meydana gelen kalıntı gerilmelerden kaynaklandığ 1 gözlenmiştir.

Anahtar Kelimeler: Nakajima Testi, Şekillendirme Sınır Eğrisi (ŞSE), Minimum Majör Değeri, Al 2024-T4.

\section{INVESTIGATION INTO REASONS FOR MINIMUM MAJOR STRAIN OFFSETTING OF FORMING LIMIT CURVE OBTAINED WITH NAKAJIMA TEST FOR AA 2024-T4}

\begin{abstract}
In a typical forming limit curve (FLC), the minimum major strain where the minor value is equal to zero is located at $y$ axes. In many forming processes, failure occurs at this region. Many studies in literature indicates that minimum major strain value is obtained about at y axis. In this study, the minimum major strain value is not determined on the $y$ axes and it was found to be offsetted from the $y$ axes to the right about 0.04 strain for AA 2024-T4. This value could be important for evaluations of sheet metal forming processes. In this study, the reasons for the minimum major strain of setting of the forming limit curve for AA 2024-T4 were investigated. It was found that drawbead and heat treatment were most effective parameters for this offsetting. It is observed that offsetting result from pre-strain which occur for conducted tests with using draw-bead and residual stress arising from T4 heat treatment.
\end{abstract}

Keywords: Nakajima Test, Forming Limit Curve (FLC), Minimum Major Strain, AA2024-T4

\section{GIRIŞ̧ (INTRODUCTION)}

Geçmiş yıllarda çoğunlukla sac metal kalıp tasarım ve imalatı deneme yanılma yöntemi ile yapılırken, teknolojinin gelişmesiyle birlikte günümüzde kalıpların performansları daha üretilmeden bilgisayar ortaminda test edilebilmektedir. Bunun sonucunda ortaya çıkabilecek kusurlar önceden tahmin edilerek 
önlemler alınabilmektedir. Kalıp tasarımının bilimsel temellere dayandirılması sonucu deneme yanılma sayısı azaltılarak zaman, iş gücü ve maliyet açısından tasarruf sağlanmaktadır[1,2]. Sonlu elemanlar analizlerinin (SEA) gerçekleştirilebilmesi için prosesin doğru olarak tanımlanması, malzeme ve proses parametrelerinin programa girilmesi gerekmektedir[3]. Sac metal şekillendirme simülasyonlarında sonuçların yorumlanması için kullanılacak malzemeye ait şekillendirme sınır eğrisi (ŞSE) programa girilerek elde edilen sonuçlar bu eğriyle bire bir karşılaştırılabilmektedir. $\mathrm{Bu}$ eğri ilk olarak, Keeler ve Backofen[4] tarafindan sac metallerin şekillendirilebilirliğini değerlendirmek amacıyla ortaya atılmıştır. ŞSE, tek eksenli çekmeden düzlem birim şekil değiştirme $\left(\mathrm{SSSE}_{0}\right)$ ve iki eksenli gerdirme bölgeleri boyunca malzemenin majör ve minör sınır birim şekil değiştirmelerin (BŞD) tüm kombinasyonlarını içermektedir[5]. ŞSE'ler şekillendirilebilmenin değerlendirilmesi ve üretim problemlerinin belirlenmesi amaciyla sac metal şekillendirme analizlerinde yaygın olarak kullanılmaktadır. Değerlendirmenin hassasiyeti programa girilen ŞSE'nin doğruluğuyla doğrudan orantilidir.

ŞSE'lerin deneysel olarak elde edilmesi uzun ve zahmetli bir iş olduğu için araştırmacılar ŞSE'leri teorik veya nümerik modeller kullanarak elde etme yoluna gitmişlerdir. Ancak ŞSE'ler modellerde kullanılan akma kriterlerine göre oldukça farklılık gösterebilmektedir[3]. Henüz genel kabul görmüş bir model geliştirilemediğinden dolayı halen ŞSE'leri deneylerden elde etmek en sağlıklı yöntem olarak görülmektedir[6]. ŞSE'ler, Nakajima (gerdirme) veya Marciniak (derin çekme) testlerinden elde edilebilmektedir[4]. Marciniak testinde kalıp setinin düz olması sebebiyle bükülmenin etkisi oluşmamaktadır. Bu testte, ara sac kullanarak numune ile kalıp arasındaki sürtünme etkisi ortadan kaldırılarak ŞSE elde edilmektedir. Bu çalışmada, gerçek şekillendirme proseslerine yakın olması ve geniş bir aralıkta BŞD yolu elde edilebilmesi ve stampa ile sac arasında ISO 12004-2 standardında da belirtildiği gibi oldukça düşük bir sürtünme sağlanabilmesinden dolay1[7], Nakajima testi kullanılmıştır. Nakajima testlerinde sac numune baskı plakası ve kalıp arasında kilitlenerek, sacın kalıp içerisine akışı engellenmekte ve numune küresel bir stampa ile hasar oluşuncaya kadar şekillendirilmektedir[1]. Çeşitli numune geometrileri kullanılarak, tek eksenli çekmeden eşit iki eksenli gerdirme bölgesine kadar farklı BŞD yolları oluşturulması sağlanmaktadır[8].

Alaşımlı alüminyumlar yüksek mukavemet / ağırlık oranı, yüksek fiziksel ve mekanik özellikleri, iyi korozyon direnci, hafif ve ucuz olması, 1sıl işlemler sonucu mekanik özelliklerinin iyileștirilerek daha yüksek dayanımlar elde edilebilmesi gibi özelliklere sahiptir[9,10]. Ancak bu alaşımların şekillendirilebilirliği düşük karbonlu sac çeliklere göre oldukça düşüktür. Al 2024, havacılık endüstrisinde yüksek mukavemet/ağırlı oranı gerektiren parçalar için özellikle uygundur ve ticari ve savunma uçaklarında gövde ve kanatlarda yaygın olarak kullanılan alaşımlardan birisidir[10].

Tipik bir ŞSE'de, en düşük (minimum) majör birim şekil değiştirme değeri, minör BŞD değerinin sıfır olduğu $y$ ekseni üzerinde olmalıdır ve bu nokta düzlem birim şekil değiştirme ( $\left.\mathrm{SSE}_{0}\right)$ durumu olarak adlandırılır. Çoğu şekillendirme proseslerinde hasar, kritik bir durum olan düzlem BŞD bölgesinde meydana gelmektedir. Sonlu elemanlar analizlerinin gerçeğe yakın ve hassas sonuçlar verebilmesi için yazllımlardaki malzeme ve proses parametrelerinin doğru olarak belirlenmesi son derece önemlidir[3]. Literatürde birçok çalışmadaki ŞSE'lerde en düşük majör seviyesi hemen hemen $y$ ekseni üzerinde elde edilmiştir. Bu çalışmada Şekil 1.'de görüleceği üzere literatürden farklı olarak Al 2024-T4 için minimum majör BŞD değeri, $y$ ekseninden yaklaşık olarak 0,040 BŞD sağa doğru ötelenmiş olarak elde edilmiştir. $\mathrm{Bu}$ değer sac metal şekillendirme işlemlerinin değerlendirilmesinde önemli olabilmektedir. Bu çalışmada Al 2024-T4 sac metalin en düşük majör birim şekil değiştirme değerinin literatürden farklı olarak sağa ötelenmiş olarak elde edilmesinin nedenleri araştırılmıştır.

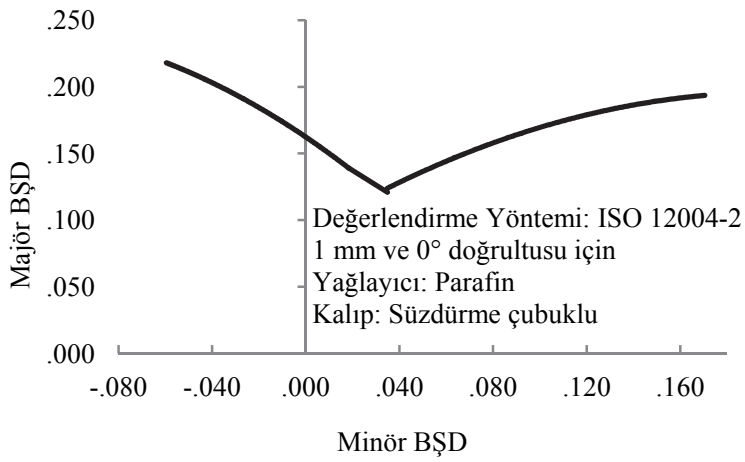

Şekil 1. Al 2024-T4 için ŞSE (Forming limit curve for AA 2024-T4)

\section{MALZEME VE YÖNTEM (MATERIAL AND METHOD)}

\subsection{Malzeme ve Şekillendirme Prosesi (Material and Forming Process)}

Bu çalışmada kullanılan Al 2024 alaşımı T3 formunda temin edilmiştir ve çökelme sertleşmesi isıl işlemi uygulanmıştır. Sac malzemeler $493{ }^{\circ} \mathrm{C}$ 'de 30 dakika solüsyona alınarak suda hızlı bir şekilde soğutulmuş ve doğal yaşlandırma işlemine tabi tutulmuştur. Böylece alaşım T4 temperine dönüştürülmüştür. 
2.2. Nakajima Testlerinin Yapılması ve Sınır BŞD lerin Belirlenmesi (Conducting the Nakajima Experiments and Determination of Limit Strains)

Şekillendirme sınır eğrileri ASTM E 2218-02 (Ağustos 2002) ve ISO 12004-2 (Ekim 2008) standartlarına göre değerlendirme yapılarak elde edilebilmektedir. Dilmec ve ark.[11] iki standardın detaylı incelemesini ve karşılaştırmasını yapmışlardır. Sonuç olarak, ŞSE'lerin ISO standardına göre oluşturulmasının daha güvenilir sonuçlar verdiğini tespit etmişlerdir. $\mathrm{Bu}$ nedenle bu çalışmada ŞSE'ler ISO standardına göre oluşturulmuştur. Testlerde kullanılan Nakajima numune takımı Şekil 2.'de verilmiştir. Numunelerin her biri $175 \mathrm{~mm}$ çapa ve 25, $50,75,100,125,150$ ve $175 \mathrm{~mm}$ genişliklere sahiptir.

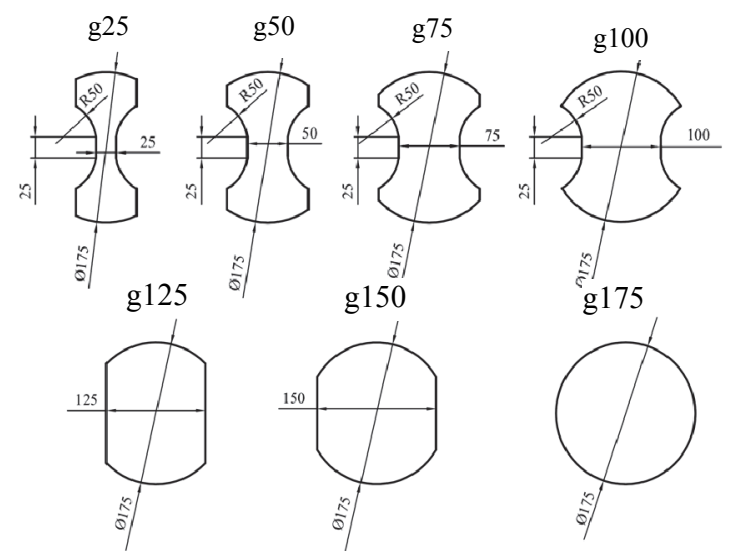

Şekil 2. ISO 12004-2 standardında belirtilen Nakajima test numune geometrileri (The Nakajima test specimen' geometries specified in ISO 12004-2)

$\mathrm{Bu}$ standarda göre değerlendirmede numunenin boyunlaşma veya yırtık bölgesine dik çizilen birkaç ortogonal kesitteki majör ve minör BŞD'lerin 1. ve 2 . türevleri alınarak elde edilen noktalardan çizilen parabolün tepe noktası sınır BŞD değeri olarak alınmaktadır (cross-section method). Ancak bu değerlendirme işleminin el ile yapılması oldukça zahmetli ve uzun sürmektedir. Bu işlemi hızlı ve hassas olarak otomatik yapabilen ARAMIS adında gerçek zamanlı ölçme sistemi geliştirilmiştir. Gerçek zamanlı ölçme testleri Atılım Üniversitesi Metal Şekillendirme Mükemmeliyet Merkezi'nde bulunan ve Şekil 3a.'da görülen ARAMIS ekipmanı ve yazılımı kullanılarak yapılmıştır. Numunelerin bir yüzeyi önce beyaz bir boya püskürtülerek boyanmış, sonra Şekil 3b.'de görüldüğü gibi siyah boya ile rastgele benekli bir yapı oluşturulmuştur. Şekillendirme sırasında yüksek çözünürlüğe sahip CCD dijital kameralar kullanılarak numune üzerine oluşturulan bu benekli yapıların görüntü işleme yöntemleriyle takip edilerek BŞD’ler otomatik olarak belirlenebilmektedir. Sac metalin kalıp içerisine akışını engellemek amacıyla numuneler süzdürme çubuklu bir baskı plakası ile bastırılmış ve yarı küresel bir stampayla yırtık oluşuncaya kadar şekillendirilmiştir. Testler $60 \mathrm{~mm} / \mathrm{dk}$ hız ve $150 \mathrm{kN}$ baskı plakası kuvvetinde, numune ve stampa yüzeyleri 0,02 ila 0,05 gibi oldukça düşük sürtünme katsayısına sahip parafin[12] ile yağlanarak ve saniyede 5 fotoğraf çekilerek gerçekleştirilmiştir. Sürtünme katsayısının çok düşük olması sebebiyle, testler sonucunda tüm numuneler, ISO 12004-2 standardında belirtildiği gibi, kubbe tepe noktasına oldukça yakın bölgeden yırtılmıştır. Böylece Marciniak testindeki sürtünmesiz koşul elde edilebilmiştir.

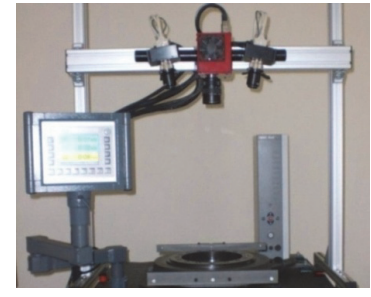

a)

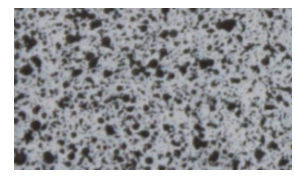

b)
Şekil 3. a) Yüksek çözünürlüklü CCD kameralara sahip ARAMIS sistemi (ARAMIS system with high resolution CCD cameras), b) Numune yüzeyine oluşturulan benekli yap1 (Speckle pattern composed on the specimen' surface)

Gerçek zamanlı ölçme sistemi ilk ve yırtıktan bir önceki fotoğraf arasındaki kayma, dönme ve çarpılmaları kullanarak parça üzerindeki BŞD dağılımını hesaplamaktadır. Yırtıktan bir önceki fotoğraftaki sınır BŞD değerini belirlemek için, ISO standardında belirtildiği gibi, dar numunelerde kenara paralel ve geniş numunelerde yırtığa dik olacak şekilde en az $20 \mathrm{~mm}$ uzunluğunda üç kesit çizilmiştir (cross-section method) (Şekil 4a.). Sınır BŞD’ler, bu kesitler boyunca majör ve minör BŞD'lerin 1. ve 2 . türevleri alınarak elde edilen noktalardan çizilen parabolün tepe noktası olarak yazılım tarafindan otomatik olarak Şekil 4b.'deki gibi belirlenir. Microsoft Excel programında elde edilen sınır BŞD'lere en uygun eğri belirlenerek SŞE'ler elde edilmiştir.

2.3. En Düşük Majör Değerinin Ötelenme Nedenlerini Araştırmak İçin Yapılan Testler (Conducting Experiments to Investigate for Minimum Major Strain Offsetting)

İlk olarak Al 2024-T4 malzemesindeki bu davranışın T4 ısıl işlemi sonucu meydana gelen kalıntı gerilmeler olabileceği düşünülmüştür. Bunun için T3 temperi için süzdürme çubuklu baskı plakası kullanılarak ŞSE oluşturulmuştur. Buna ilaveten en düşük majör BŞD'deki ötelenme miktarının, numuneyi suya daldırma doğrultusundan etkilenebileceği düşüncesiyle, $0^{\circ}$ doğrultusunda hazırlanan g125 numuneleri solüsyona alma işleminden sonra, yan ve dik doğrultularda suya daldırılmıştır. Yaşlanma işlemi tamamlandıktan sonra bu numuneler şekillendirilmiş ve sınır BŞD'ler belirlenmiştir. 
İkinci olarak, stampayla şekillendirme işleminden önce, numune üzerine süzdürme çubuklu kalıpla bastırma işleminin numunede meydana getirdiği ön BŞD'nin ŞSE'yi önemli ölçüde etkileyebileceği düşünülmüştür. $\mathrm{Bu}$ amaçla ilk olarak T4 temperi durumundaki ŞSE $\mathrm{S}_{\mathrm{o}}$ bölgesini oluşturan g125 numuneleri üzerinde sadece süzdürme çubuğu ile bastırmanın etkisi incelenmiştir. Ön BŞD’nin etkisini ŞSE üzerinde daha açık şekilde incelemek amacıyla süzdürme çubuksuz (düz) baskı plakası kullanılarak T4 temperi için ŞSE elde edilmiştir.

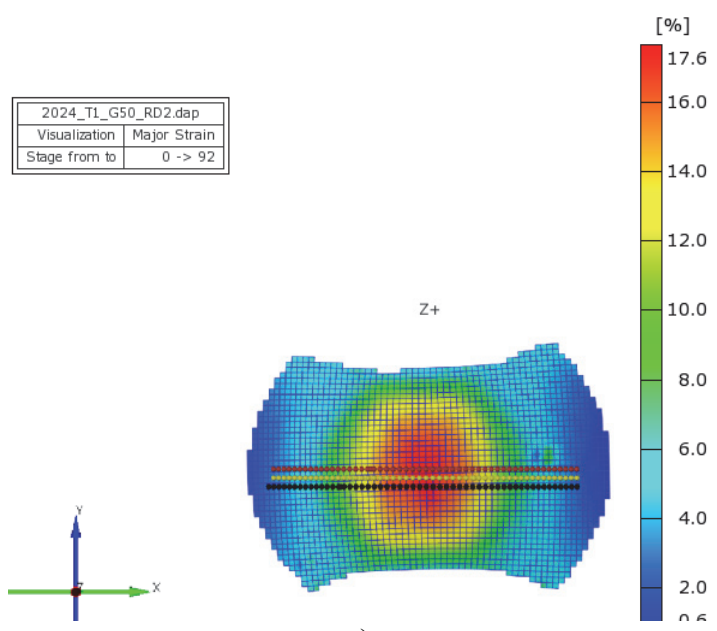

a)
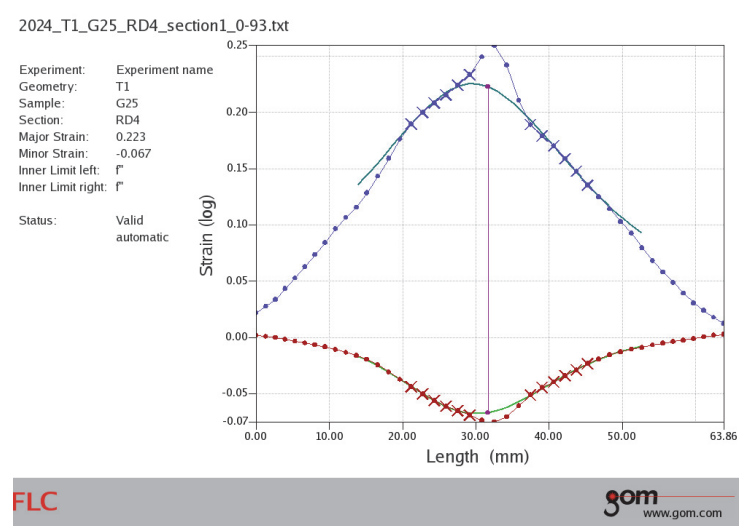

b)

Şekil 4. a) Numunelerin üzerinde yırtığa dik çizilen ortogonal kesitler (The orthogonal sections drawn perpendicular to the fracture on the specimens), b) BŞD'lerin 1. ve 2. türevleri alınarak sınır BŞD'nin elde edilmesi (Determination of the limit strains using first and second derivate of the strains)

Isıl ișlemin ve süzdürme çubuğu ile bastırma sonucu oluşan ön BŞD'nin etkilerini ayrı ayrı inceledikten sonra, T3 temperi için düz baskı plakası kullanılarak da ŞSE'ler elde edilmiştir. Ayrıca O temperi durumunda temin edilen Al 2024 malzemeler için de düz baskı plakası kullanılarak ŞSE elde edilmiştir. Sacın kalıp içerisine akışını engellemek amacıyla düz bask1 plakasında yapılan testlerde $250 \mathrm{kN}$ 'luk bask1 plakası kuvveti uygulanmıştır.
Yapılan tüm denemeler sonucunda, en düşük majör BŞD seviyesinin sağa ötelenme miktarı azalsa da yine de belli bir miktar kalmaktadır. $\mathrm{Bu}$ etkinin, sacın stampanın şeklini alarak eğilmesi sonucu, numunenin diş ve stampa ile temasta olan iç yüzeylerinde oluşan BŞD'lerin farklı olmasından kaynaklandığ düşünülmüştür. $\mathrm{Bu}$ etkiyi deneysel olarak görmek amacıyla, 0,8 ve $2 \mathrm{~mm}$ sac kalınlıkları için en düşük majör BŞD seviyesini oluşturan g100 ve g125 numunelerinin her iki yüzeyine de serigrafi yöntemiyle 2,5 mm kare grid yapısı oluşturulmuştur. Yazarların da aralarında bulunduğu, Öztürk ve ark.[13] çalışmalarında, serigrafi yöntemi ile elde edilen gridlerin şekil değiştirme sonunda ve özel asitlerle ovalayarak bile ortadan kalkmadiğı gözlemlemişlerdir. Bu yöntemle grid yapısının, \% 95 güvenilirlikle doğruluğu $0,01 \mathrm{~mm}$, tekrarlanabilirliği de $0,006 \mathrm{~mm}$ olarak elde edilmiştir. Bu çalışmada da gridler aynı şekilde edilerek ölçümler yapılmıştır.

Şekillendirme işleminden önce stampa ile temasta olan bölgede sürtünme etkisiyle gridlerin ortadan kaybolmaması amacıyla, parafin yağlayıcısı ile yağlanan iç yüzey çok katlı ince streç film ile kaplanmıştır. Şekillendirme sonunda streç film ile kaplanan iç yüzeydeki gridler bozulmamıştır (Şekil 5.).

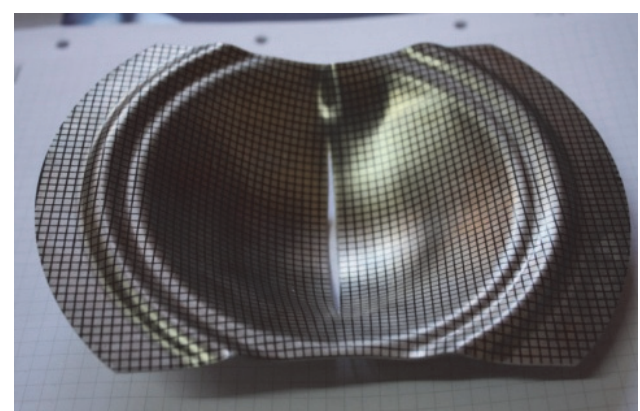

Şekil 5. Stampayla temas eden iç yüzeydeki grid yapısının bozulmadığı örnek bir numune (A sample specimen which its grid pattern does not disappear)

Şekillendirme sonunda sacın iç ve dış yüzeyindeki gridlerde meydana gelen BŞD'lerin ARAMIS yazılımıyla ölçülmesi mümkün olmamaktadır. Bu nedenle numunelerin iç ve diş yüzeylerindeki BŞD dağılımları, bilgisayarlı grid analiziyle ölçme yapan ASAME 4.1. yazılımı kullanılarak elde edilmiştir. BŞD dağılımları, ölçme yapılacak bölgenin yakınına referans küpü yerleştirilerek, ölçme alanı ve referans küpünü kapsayacak şekilde en az iki farklı açıdan çekilen fotoğrafların ASAME programında işlenmesiyle elde edilmiştir. Dilmeç[14] ve Dilmeç ve ark.[15] çalışmalarında bu işlemin detayları verilmiştir. BŞD dağılımları elde edildikten sonra, numunenin orta kisminda, kubbe tepe noktasindan flanş bölgesine kadar tanımlanan bir kesit boyunca iç ve dış yüzeylerdeki minör ve majör BŞD değerleri elde edilerek eğriliğin etkisi ortaya koyulmuştur. Sınır BŞD değeri, Dilmec ve ark.[11] tarafindan önerilen yönteme göre elde edilmiştir. Araştırmacılar önerilen 
yöntemin doğruluğunu ARAMIS yazılımıyla elde edilen değerleri referans alarak göstermişlerdir. Sonuç olarak önerilen yönteme göre elde edilen sınır BŞD'ler ARAMIS ile elde edilenlerle oldukça uyumlu ve güvenilir olacaktır. Bütün testler $0,8 \mathrm{~mm}$ sac kalınlığ 1 ve $0^{\circ}$ doğrultusu için ve 3 başarılı tekrar elde edecek şekilde yapılmıştır.

Ötelenmenin sebeplerini araştırmak için sırasıyla yapılan incelemeler özet olarak Tablo 1.'de verilmiştir.

\section{BULGULAR VE TARTIŞMA (RESULTS AND DISCUSSION)}

Malzemeye ait kimyasal ve ASTM E 8M-04 standardına uygun olacak şekilde elde edilen mekanik özellikler sırasıyla Tablo 2. ve 3.'te verilmiştir.

\section{1. İlave numune genişliklerinin ŞSE'de etkisi (Effect of Additional Specimen Widths on FLD)}

İlk oluşturulan ŞSE'lerde en düşük majör BŞD değeri $y$ ekseninden yaklaşık olarak 0,025 BŞD sağa doğru ötelenmiş durumda elde edilmiştir. En düşük majör BŞD'nin yerinin hassas olarak belirlenmesi amaciyla, ŞSE'lerin elde edilmesinde kullanılan $25 \mathrm{~mm}$ artıml standart genişlikli numunelerin $(\mathrm{g} 25, \mathrm{~g} 50, \ldots ., \mathrm{g} 175)$ yanında, bu bölgede g125 ile g143 genişlikleri arasında 2'şer mm artan genişliğe sahip standart diş1 ilave genişlikler için de testler yapılmıştır. Süzdürme çubuğunun diş çap1 133 mm olduğundan, g133 g175 numuneleri arasında bir fark olmaması gerektiği düşünülebilir. Yüksek baskı plakası kuvvetlerinde numuneler süzdürme çubuğu bölgesinden yırtılmakta, düşük baskı plakası kuvvetlerinde ise, süzdürme çubuğu numunelerin kalıp içerisine akışı tam olarak engelleyememektedir. Bu problem sadece g133'ten büyük numuneler için meydana gelmektedir. Numunelerin kalıp içerisine çekilme miktarı bilinmezken, bu çekilme miktarının sınır BŞD'ler üzerinde etkisi olmadığı görülmüştür. Diğer numuneler için yapılan testlerde numunenin kalıp içerisine akışı tam olarak engellenmektedir. g133 g143 numuneleri arasında 2'şer mm aralıklarla yapılan ve g150 için yapılan testlerde eğrinin sağ tarafında ilave sınır BŞD'ler elde edilerek eğrinin belirsizliği ortadan kaldırılmıştır. g133'ten büyük numuneler için yapılan testlerde numunenin tamamı süzdürme çubuklu bölgeye girdiğinden iki eksenli gerilme durumu oluşmuştur. Bu nedenle sınır BŞD'ler eğrinin minimum noktasının hemen sağ tarafinda elde edilemeyip eşit iki eksenli bölgeye yakın tarafta elde edilebilmiştir. Sonuç olarak g133'e kadarki numunelerden eğrinin minimum noktasının elde edildiği söylenebilir. Bu testlerin sonucunda en düşük majör BŞD değeri daha da sağa ötelenerek 0,04 BŞD değerine ulaşmıştır ve bu eğri standart genişlikler için elde edilenlerle ve Hursman (1978) tarafindan elde edilen ŞSE ile karşılaştırmalı olarak Şekil 6.'da verilmiştir. Her üç eğri arasında önemli oranda fark olduğu görülmektedir. Hursman tarafından elde edilen eğrinin en düşük majör $\mathrm{BŞD}$ değeri $y$ ekseni üzerindeyken, bu çalışmada ilave genişlikler kullanılarak elde edilen eğrinin en düşük majör BŞD değeri $y$ ekseninden yaklaşık 0,040 BŞD gibi önemli oranda sağa ötelenmiş olarak elde edilmiştir. Hursman tarafından elde edilen eğri, bu çalışmada ilave genişlikler kullanılarak elde edilen eğrinin $y$ ekseni üzerine ötelenmiş hali gibidir. Eşit iki eksenli gerdirme bölgesi hariç tüm bölgelerde eğriler arasında önemli ölçüde farklar vardır.

Sol taraf ve en düşük majör BŞD bölgesi için Hursman tarafından elde edilen eğri bu çalışmada elde edilene göre emniyetli tarafta kalırken, eğrinin sağ tarafında tersi bir durum söz konusudur. Sol taraf ve en düşük majör BŞD bölgesinde bu çalışmada elde edilen eğrinin daha güvenilir olması durumunda, Hursman tarafından elde edilen eğri kullanıldığında şekillendirilebilirlikten tam olarak faydalanılamayacaktır. Tersi durumda ise bu çalışmada elde edilen eğri güvenilir sonuçlar vermeyecektir. Elde edilen eğrilerden hangisinin güvenilir olduğunu belirlemek amacıyla klasik derin çekme prosesi için durum çalışması yapılmıştır. Dairesel numuneler $60 \mathrm{~mm}$ çapa sahip silindirik stampayla şekillendirilmiştir. İlkel çaptan biraz büyük

Tablo 1. En düşük majör BŞD değerinin ötelenme sebeplerinin incelenmesinde izlenen yol (Methods for investigation into reasons for minimum major strain offsetting)

\begin{tabular}{|l|l|}
\hline Ötelenme sebebi & Yapılan işlem \\
\hline $\begin{array}{l}\text { En düşük majör BŞD'deki ötelenme, T4 } \\
\text { temperine dönüştürme sonucunda oluşabilir. }\end{array}$ & $\begin{array}{l}\text { T3 temperi durumunda malzemenin süzdürme çubuklu kalıp } \\
\text { kullanılarak ŞSE’si oluşturulmuştur. }\end{array}$ \\
\hline $\begin{array}{l}\text { En düşük majör BŞD'deki ötelenme, } \\
\text { numuneyi suya daldırma doğrultusundan } \\
\text { etkilenebilir. }\end{array}$ & $\begin{array}{l}\text { Numuneler yan ve dik doğrultularda suya daldırılarak sınır BŞD'ler } \\
\text { belirlenmiştir. }\end{array}$ \\
\hline $\begin{array}{l}\text { Süzdürme çubuğu ile uygulanan ön gerilme } \\
\text { ötelenmeyi etkileyebilir. }\end{array}$ & $\begin{array}{l}\text { Sadece süzdürme çubuğu ile bastırılan ve başkaca şekillendirilmeyen } \\
\text { numunelerdeki BŞD ölçülmüştür. }\end{array}$ \\
\cline { 2 - 2 } $\begin{array}{l}\text { T4 temperi için, düz baskı plakası kullanılarak ŞSE elde edilmiştir. } \\
\text { etkişi }\end{array}$ & T3 temperi için düz baskı plakası kullanılarak ŞSE elde edilmiştir. \\
\hline T3 ve T4 temperlerinin etkisi & O temperi için düz baskı plakasıı kullanılarak ŞSE elde edilmiştir. \\
\hline \multirow{2}{*}{ Eğilme gerilmelerinin etkisi } & $\begin{array}{l}\text { En düşük ve en büyük sac kalınlıkları için her iki yüzeyi de gridlenerek } \\
\text { şekillendirilmiş numunelerin iç ve dış yüzeylerindeki sinır BŞD'ler } \\
\text { belirlenmiştir. }\end{array}$ \\
\hline
\end{tabular}


Tablo 2. Al 2024-T4 sac malzemenin kimyasal kompozisyonu (\%) (The chemical composition of AA2024-T4 sheet (wt \%))

\begin{tabular}{|c|c|c|c|c|c|c|c|c|c|}
\hline & $\mathrm{Cu}$ & $\mathrm{Mg}$ & $\mathrm{Mn}$ & $\mathrm{Fe}$ & $\mathrm{Si}$ & $\mathrm{Zn}$ & $\mathrm{Ti}$ & Diğer & $\mathrm{Al}$ \\
\hline Elde edilen & $4,34-4,44$ & $1,23-1,34$ & $0,62-0,63$ & $0,12-0,17$ & $0,058-0,068$ & $0,077-0,092$ & $0,024-0,029$ & $0,035-0,070$ & $93,29-93,39$ \\
\hline $\begin{array}{c}\text { ASTM B } \\
\text { 209M-07 }\end{array}$ & $3,8-4,9$ & $1,2-1,8$ & $0,3-0,9$ & 0,5 & 0,5 & 0,25 & 0,15 & 0,15 & $90,85-93$ \\
\hline
\end{tabular}

Tablo 3. Al 2024-T4 sac malzemenin mekanik özellikleri (The mechanical properties of the AA2024-T4 sheet)

\begin{tabular}{|c|c|c|c|c|c|c|}
\hline & $\begin{array}{c}\text { Haddeleme } \\
\text { doğrultusu ile } \\
\text { yapılan aç1 }\end{array}$ & $\begin{array}{c}\text { Gerçek akma } \\
\text { mukavemeti } \\
\sigma_{a}(\mathrm{MPa})\end{array}$ & $\begin{array}{c}\text { Gerçek çekme } \\
\text { mukavemeti } \\
\sigma_{u}(\mathrm{MPa})\end{array}$ & $\begin{array}{c}\text { Toplam gerçek } \\
\text { uzama } \\
\varepsilon_{g}\end{array}$ & $\begin{array}{c}\text { Pekleşme katsayıs1 } \\
n\end{array}$ & $\begin{array}{c}\text { Mukavemet } \\
\text { katsayıs1 } \\
K(\mathrm{MPa})\end{array}$ \\
\hline \multirow{3}{*}{ Elde edilen } & $0^{\circ}$ & $263 \pm 5$ & $497 \pm 4$ & $0,1685 \pm 0,007$ & $0,20 \pm 0,004$ & $762 \pm 3$ \\
\cline { 2 - 7 } & $45^{\circ}$ & $249 \pm 4$ & $473 \pm 5$ & $0,1815 \pm 0,027$ & $0,20 \pm 0,004$ & $738 \pm 2$ \\
\hline \multirow{2}{*}{$\begin{array}{c}\text { ASTM B 209M-07 } \\
(0,5-1,6 \mathrm{~mm})\end{array}$} & - & $264 \pm 3$ & $502 \pm 6$ & $0,1713 \pm 0,02$ & $0,21 \pm 0,004$ & $719 \pm 3$ \\
\hline
\end{tabular}

bir çap değeri alınarak bazı parçalar hasara uğratılırken, sınır çekme oranına yakın hasarsız parçalar da elde edilmiştir. Numunelerin üzerine şekillendirme işleminden önce serigrafi yöntemiyle 2,5 mm kare grid yapısı oluşturulmuştur. ASAME yazılımıyla ölçülen parçalardaki BŞD dağılımları eğrilerin olduğu diyagram üzerine aktarılmıştır.

Sol taraf ve en düşük majör BŞD bölgesi için Hursman tarafından elde edilen eğri bu çalışmada elde edilene göre emniyetli tarafta kalırken, eğrinin sağ tarafinda tersi bir durum söz konusudur. Sol taraf ve en düşük majör BŞD bölgesinde bu çalışmada elde edilen eğrinin daha güvenilir olması durumunda, Hursman tarafindan elde edilen eğri kullanıldığında şekillendirilebilirlikten tam olarak faydalanılamayacaktır. Tersi durumda ise bu çalışmada elde edilen eğri güvenilir sonuçlar vermeyecektir. Elde edilen eğrilerden hangisinin güvenilir olduğunu belirlemek amacıyla klasik derin çekme prosesi için durum çalışması yapılmıştır. Dairesel numuneler $60 \mathrm{~mm}$ çapa sahip silindirik stampayla şekillendirilmiştir. İlkel çaptan biraz büyük bir çap değeri alınarak bazı parçalar hasara uğratılırken, sınır çekme oranına yakın hasarsız parçalar da elde edilmiştir. Numunelerin üzerine şekillendirme işleminden önce serigrafi yöntemiyle 2,5 mm kare grid yapısı oluşturulmuştur. ASAME yazılımıyla ölçülen parçalardaki BŞD dağılımları eğrilerin olduğu diyagram üzerine aktarılmıştır.

Görüldüğü gibi yırtılmış hasarlı kaptaki BŞD dağılımı Hursman tarafindan ve bu çalışmada standart genişlikler kullanılarak elde edilen ŞSE'lerin altında kalarak güvenli görünmekte iken, ilave genişlikler kullanılarak elde edilen ŞSE, iş parçasında hasar meydana geldiğini doğrulamaktadır. Ayrıca hasarsız kaptaki BŞD'ler, Hursman (1978) tarafindan elde edilen eğrinin yukarısında kalarak hasar oluşmuş gibi gösterirken, burada elde edilen eğri parçada hasar oluşmadığını doğrulamaktadır. Durum çalışmalarıyla, bu çalışmada elde edilen eğrilerin güvenilirliği açıkça ortaya konulmuştur. Bu durumda sonlu elemanlar analizlerinde Hursman tarafindan ve sadece standart genişlikler kullanılarak elde edilen eğriler güvenilir sonuçlar vermezken, bu çalışmada elde edilen eğrinin kullanılması durumunda daha doğru tahminler yapılmış olacaktır.

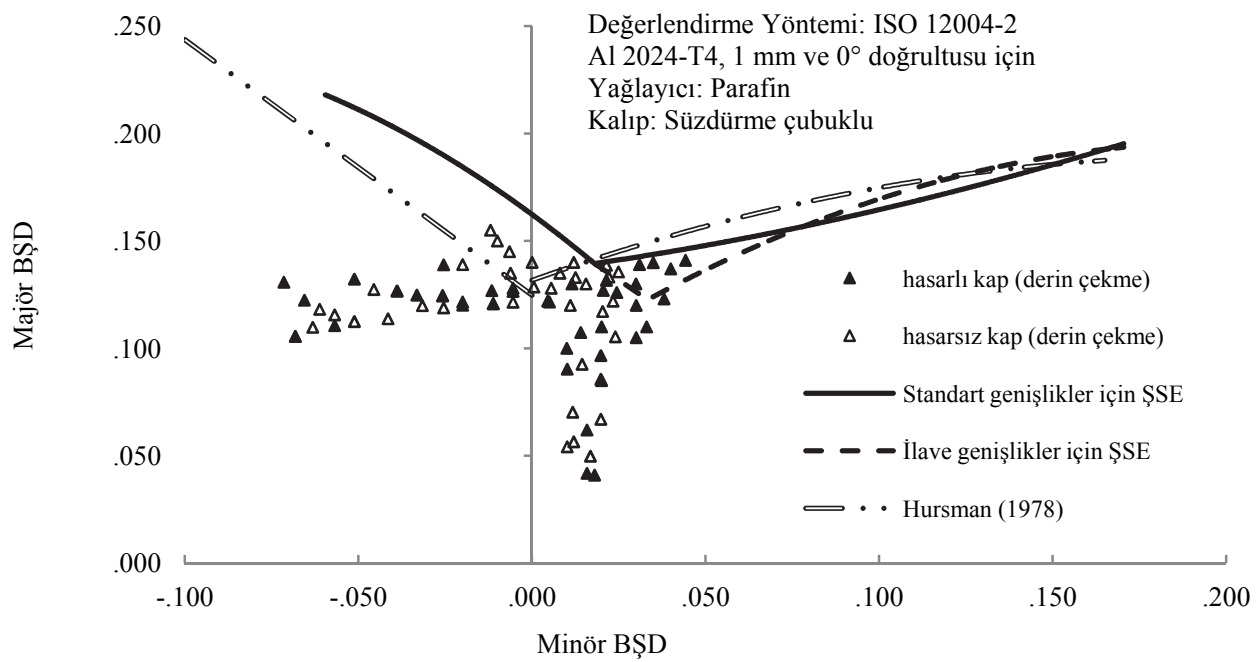

Şekil 6. İlave genişliklerle yapılan testlerin etkisi ve eğrinin literatürle karşılaştırılması (Effect of additional widths and compare the curve with curves in literature) 


\subsection{Isıl İşlem ve Süzdürme Çubuğunu ile Bastırmanın Etkisi (Effect of Heat Treatment and Press Draw-bead)}

T4 temperine dönüştürme sonucunda en düşük majör BŞD değerinde meydana gelebilecek değişikliği incelemek amaciyla, T3 temperi için elde edilen ŞSE T4 temperi ile karşılaştırmalı olarak Şekil 7.'de verilmiştir. Görüldüğü gibi T3 durumunda gerçek minör BŞD, T4 temperine göre yaklaşık olarak 0,01 minör BŞD sol tarafta elde edilmiştir. Bu farkın T4 1sıl işlemi sonucunda meydana gelen kalıntı gerilmelerden kaynaklandığı sonucuna varılabilir. $\mathrm{Su}$ verme sırasında suya daldırma doğrultusunun etkisi de incelenmiş ve etki etmediği kanaatine varılmıştır.

Süzdürme çubuğuyla malzemeye bir ön BŞD uygulanmaktadır. Bu etki incelendiğinde, Şekil 8.'de görüldüğü gibi sadece süzdürme çubuğu ile bastırılmış fakat ilave şekillendirme yapılmamış numunedeki BŞD dağılımı ortalama olarak majör ve minör BŞD'lerde sırasıyla 0,018 ve 0,0073 BŞD artış göstermiştir. Ancak buradaki artışlar ŞSE'de aynı etkiyi yapmayabilir. $\mathrm{Bu}$ amaçla T4 temperi için süzdürme çubuklu ve düz baskı plakalı (süzdürme çubuksuz) kalıp kullanarak Şekil 9.'daki ŞSE’ler elde edilmiştir.

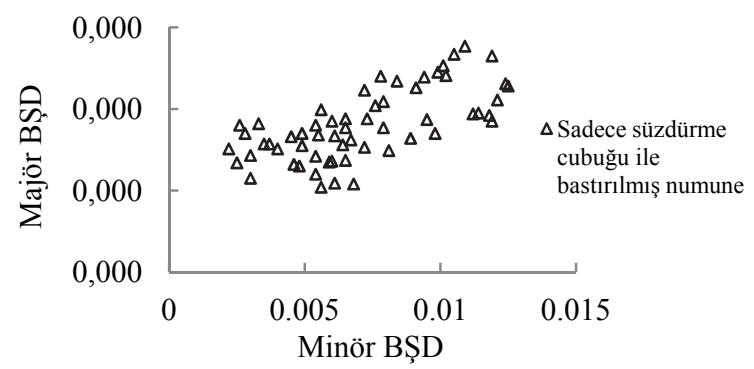

Şekil 8. Sadece süzdürme çubuğu ile bastırmanın etkisi (Effect of drawbead only)

Süzdürme çubuğu ile bastırarak ön BŞD uygulanması sonucunda, literatürde belirtildiği gibi BŞD yolları, dolayısıyla ŞSE değişiklik göstermiştir. Süzdürme çubuksuz ŞSE'deki en düşük majör BŞD seviyesi hemen hemen değişmezken, minör BŞD değeri $\sim 0,013$ BŞD sola ötelenmiştir. Bu durum Laukonis ve Ghosh[16] tarafından yapılan çalışmayla da uyumluluk göstermektedir.

Isıl işlem ve süzdürme çubuklu kalıpla bastırmanın etkisini beraberce görebilmek için elde edilen ŞSE'ler Şekil 10.'da verilmiştir. En düşük majör BŞD’nin minör BŞD değeri 0,022 BŞD sola ötelenmiştir. Bu değer her iki etkinin süperpozisyonu olan 0,021 BŞD değeriyle de uyumludur.

T3 temperini elde etmek için yapılan haddeleme işlemi sırasında oluşacak ön gerilmelerin etkisini de ortadan kaldırmak için $\mathrm{O}$ temperi durumu incelenmiştir ve süzdürme çubuksuz kalıpla oluşturulan ŞSE'si Şekil 11.'de verilmiştir. O temperine dönüştürmeyle ön gerilme ve olası kalıntı gerilmelerin giderilmesi sonucunda en düşük majör BŞD seviyesinin $y$ ekseni üzerinde yer alması beklenmekteydi. Ancak ötelenme miktarı yaklaşık 0,014 BŞD civarında elde edilmiştir. Bu durumda T3 temperine dönüştürme ile oluşan ön gerilmelerin ötelenme miktarı üzerinde 0,004 BŞD gibi çok az bir etkisi olduğu söylenebilir.

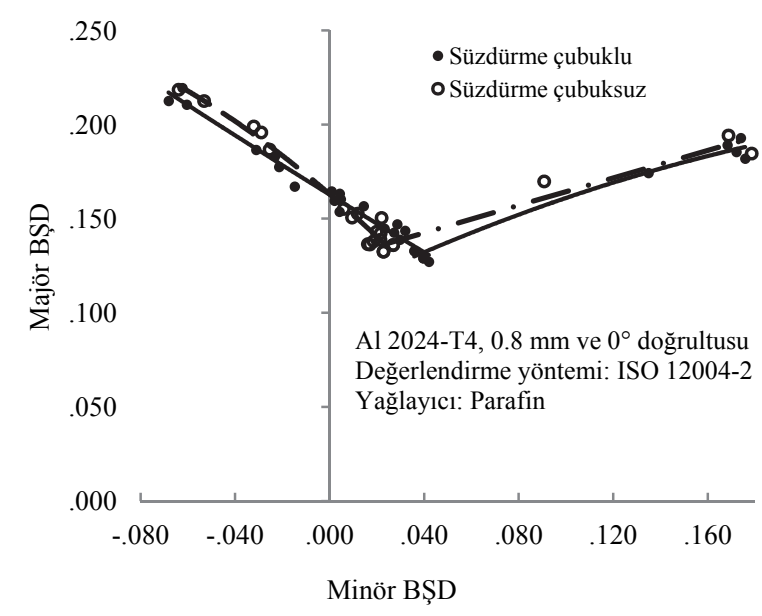

Şekil 9. Süzdürme çubuklu ve süzdürme çubuksuz elde edilen ŞSE'ler (FLCs with drawbead and without drawbead)

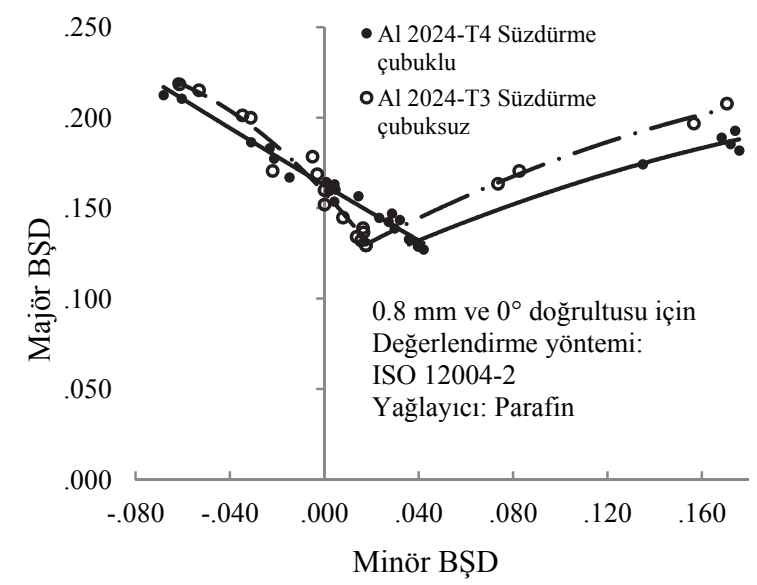

Şekil 10. T4 süzdürme çubuklu ve $\mathrm{T} 3$ süzdürme çubuksuz elde edilen ŞSE'ler (FLCs with drawbead for T4 temper and without drawbead for T3 temper)

\subsection{Bükülmenin Etkisi (Effect of Bending)}

Minör BŞD değerinin ötelenmesinin bir nedeni de sacın stampanın şeklini alarak eğilmesi ile açıklanabilir. Düzlem BŞD sacın iç veya diş yüzeyinde, ya da orta düzleminde meydana gelebilir. Orta düzlemde meydana gelirse, iç yüzeyde basma, ölçmenin yapıldığı dış yüzeyde ise çekme BŞD’leri oluşur. İç ve diş yüzeylerdeki değerler sırasıyla, $\varepsilon=\ln (1+t / r)$ ve $\varepsilon=+\ln (1+t / r)$ veya yaklaşık olarak-t/r $v e+t / r$ olacaktır[17]. Burada $r$, stampa yarıçapıdır. Ötelemenin en çok yapılması gerektiği, düzlem BŞD’nin sacın iç yüzeyinde meydana gelmesi durumunda, dıştan ölçülen BŞD $t / d$ kadar fazla olacaktır. Burada $d$, stampa çapıdır. Bu durumda 


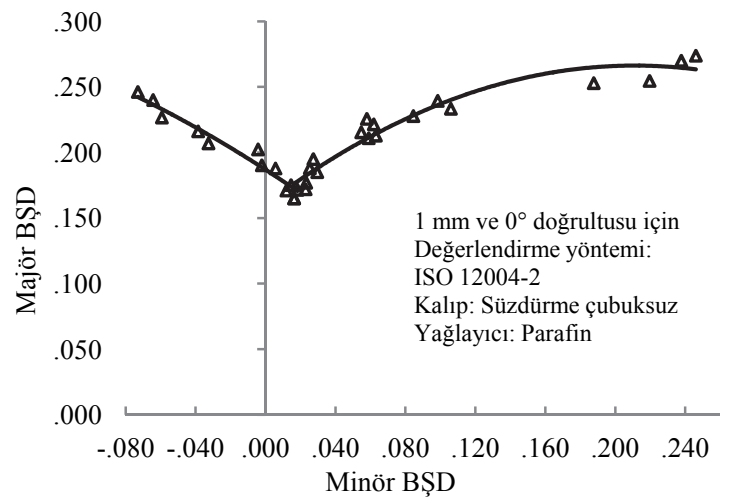

Şekil 11. Al 2024-O için ŞSE (FLC for AA 2024-O)

teorik olarak hem majör hem de minör BŞD değerleri 0,8 ve $2 \mathrm{~mm}$ kalınlıklar için sırasıyla 0,008 ila 0,02 BŞD azaltılması gerekir.

Eğriliğin etkisini deneysel olarak görmek amacıyla, 0,8 ve 2 mm'lik g100 ve g125 numunelerinin orta kesiti boyunca, grid analizi ile iç ve dış yüzeylerindeki BŞD dağılımları elde edilmiştir. Kubbe tepe noktasından geçen ve hasara dik bir kesit boyunca g125 için BȘD dağılımları Şekil 12.'de verilmiştir. Stampa ile temasta olan $50 \mathrm{~mm}$ çapındaki bir bölgede, iç yüzeydeki BŞD değerleri dış yüzeydekinden daha küçüktür. Yırtığın meydana geldiği bölgedeki iç ve dış yüzeylerdeki fark diğer bölgelere göre nispeten biraz daha azdır. Bu azalma eğiliminin geri yaylanmadan kaynaklanabileceği düşünülmektedir.

Burada numune boyunca iç ve diş yüzeylerdeki farklardan ziyade yırtık bölgesinde iç ve dış yüzeylerden belirlenecek sınır BŞD değerleri arasındaki fark önemlidir. 0,8 ve $2 \mathrm{~mm}$ kalınlıkları için en düşük majör BŞD seviyesine yakın bir değeri oluşturan g125 numunesinin yırtık bölgesinde iç ve dış yüzeylerden ölçülen sınır BŞD'ler ve hasarın oluştuğu yüzeye göre olası ötelenme değerleri Tablo 4.'te verilmiştir.

Yapılan incelemeler sonucunda, Al 2024 sac malzemeler $\mathrm{O}$ temperi durumunda şekillendirildiği ve iç yüzeyden ölçüm yapıldığı zaman, ŞSE'nin en düşük majör BŞD seviyesinin yaklaşık $y$ ekseni üzerinde olacağı düşünülmüştür. Bu amaçla $\mathrm{O}$ temperi durumunda, Şekil 9.'da görüldüğü gibi en düşük majör BŞD seviyesini oluşturan g115 numunesi süzdürme çubuksuz kalıpla şekillendirilmiş ve iç ve dış yüzeyden ölçüm alınarak sınır BȘD değeri elde edilmiştir (Tablo 5.). Görüldügü gibi isıl işlem ve ön gerdirme etkilerini ortadan kaldırılarak ve iç yüzeyden ölçüm yaparak elde edilen en düşük majör BȘD seviyesi sac kalınlığına göre $y$ eksenine yaklaşık \% 0,007 ila \% 0,014 minör kadar uzaktır. Ölçümlerde yapilan hatalar ve SSSE'lerin elde edilmesindeki 0,013 belirsizlik değeri göz önüne alındığında, bu değerler küçük kabul edilebilir. Ancak 1sıl işlem ve süzdürme çubuğu ile bastırma sonucu oluşan ötelenme büyük kabul edilebilir.

Tüm bu değerlendirmelerden sonra, Al 2024-T4'ün ŞSE'sinin en düşük majör BŞD'sinin konumunun; 1sıl işlem ve süzdürme çubuğu ile 0,023 BŞD ve diş yüzeyden ölçme yapılması sebebiyle kalınlığa göre $0 \sim 0,02$ BŞD sağa ötelendiği göz önüne alınırsa, toplam olarak yine kalınlığa göre $0,03 \sim 0,04$ BȘD sağa ötelenmesinin normal olduğu sonucuna varılmıştır.

\section{SONUC (CONCLUSION)}

- $\mathrm{Bu}$ çalışmada, Al 2024-T4 için standart genişliklerle $y$ eksenine göre 0,02 minör BŞD sağa ötelenmiş olarak elde edilen en düşük majör BȘD değerinin, ilave genişlikler için testler yapılarak 0,04 BŞD'ye çıktı̆̆ı görülmüştür. Yapılan durum çalışması sonucunda, ilave genişlikler kullanılarak elde edilen ŞSE'nin iş parçasında meydana gelen hasarları daha doğru tahmin ettiği ve daha güvenilir sonuçlar verdiği görülmüş̧ür. Sonuç olarak tüm malzemeler için ŞSE'ler elde edilirken en düşük majör BŞD değerini oluşturacak ilave genişlikler için de testler yapılmalıdır.

- $\quad$ Al 2024-T4 için en düşük majör BŞD değerinin konumunun $y$ ekseninden sağa ötelenme sebepleri

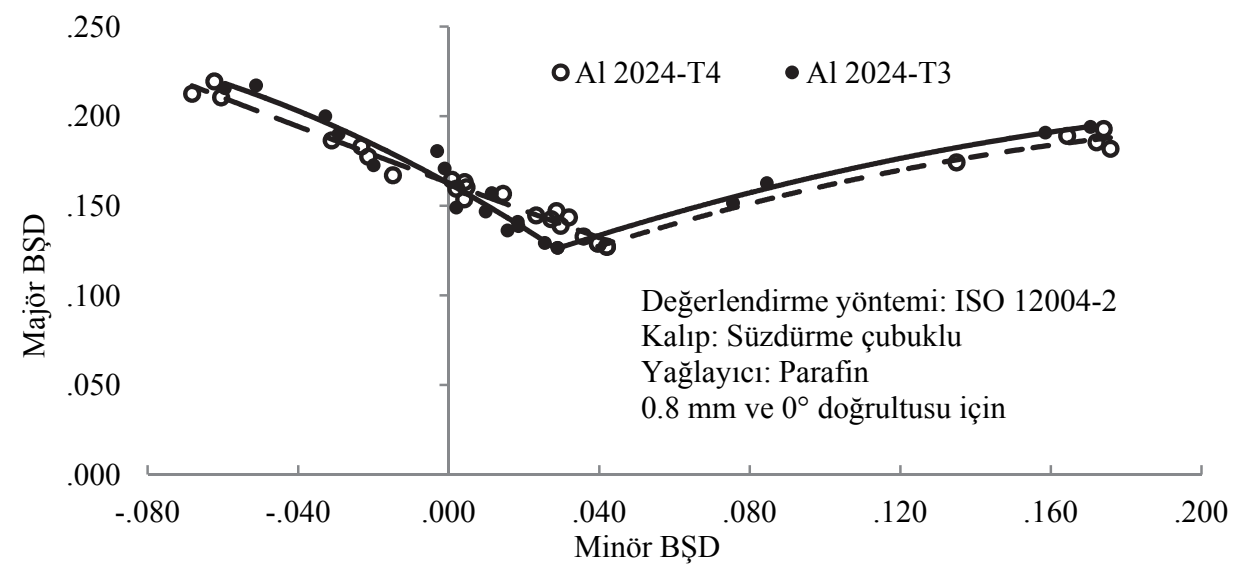

Şekil 7. $\mathrm{T} 3$ ve $\mathrm{T} 4$ temperlerinin karşılaştırılması (Comparison of the $\mathrm{T} 3$ and $\mathrm{T} 4$ tempers) 


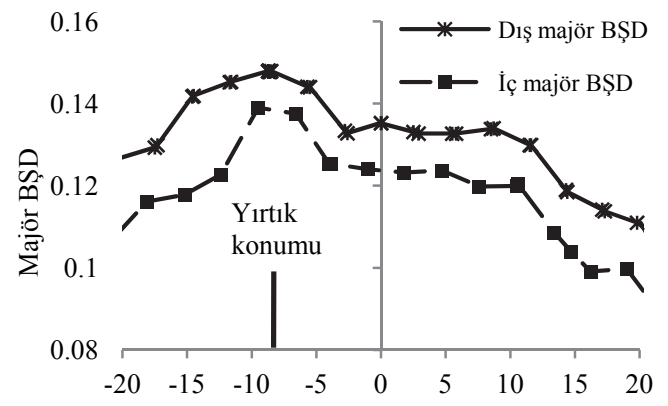

Kubbe tepe noktasına uzaklık, mm

a)

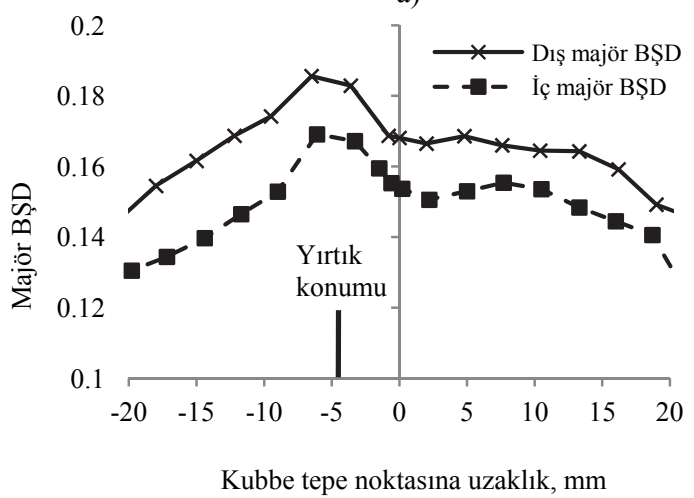

c)

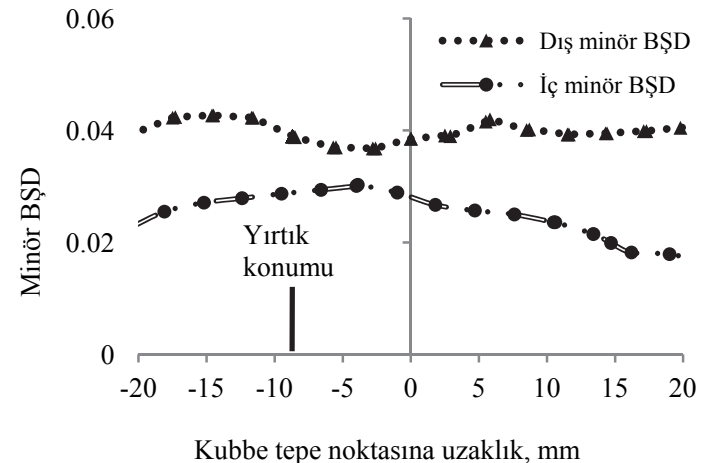

b)

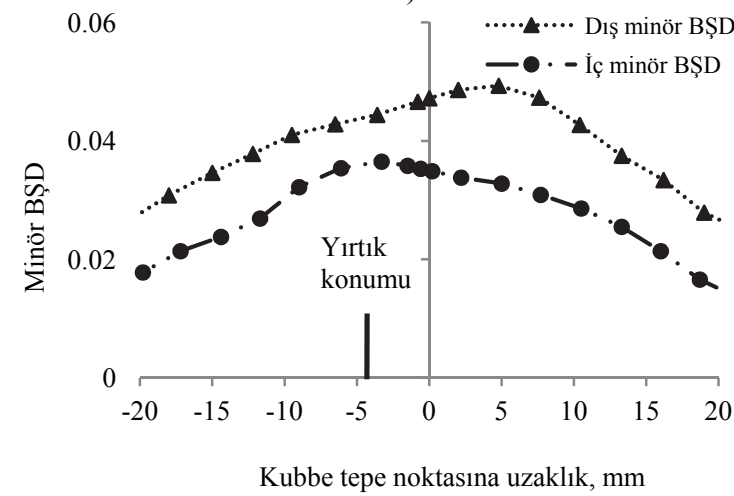

d)

Şekil 12. İç ve dış yüzeylerinden belirlenen BŞD dağılımları, a) 0,8 mm g125 majör, b) 0,8 mm g125 minör, c) $2 \mathrm{~mm}$ g125 majör, b) $2 \mathrm{~mm} \mathrm{~g} 125$ minör (Obtained a) major for $0.8 \mathrm{~mm} \mathrm{~g} 125$ and b) minor for $0.8 \mathrm{~mm}$ g125, c) major for $2 \mathrm{~mm}$ g125 and b) minor for $2 \mathrm{~mm} \mathrm{~g} 125$ strain distrubutions from the inner and outer surfaces)

araştırıldığında; numunelere uygulanan ısıl işlem, süzdürme çubuğu ile bastırarak ön gerilme oluşması bükülmenin etkisiyle eğilme gerilmelerinin oluşması ötelenmeyi artıran faktörler olarak tespit edilmiştir.

- Ötelenmeye, süzdürme çubuğu kullanılarak yapılan testlerde oluşan ön BŞD'lerin ve T4 isıl işlemi sonucunda meydana gelen kalıntı gerilmelerin neden olduğu tespit edilmiştir. En düşük majör BŞD’nin minör BŞD değerinin, 1sıl işlem ve süzdürme çubuğu ile bastırmanın etkisi ile, sırasıyla yaklaşık 0,01 ve 0,013 BŞD ve bu iki etki birlikte incelendiğinde ise $0,022 \mathrm{BŞD}$ sola ötelendiği görülmüştür. Bu durumda toplamdaki 0,040 BŞD sağa ötelenme miktarının 0,023 BŞD'lik kısmının ısıl işlem ve süzdürme çubuğuyla bastırma sebebiyle oluştuğu tespit edilmiştir.

- Ötelenmeye, süzdürme çubuğu kullanılarak yapılan testlerde oluşan ön BŞD'lerin ve T4 1sıl işlemi sonucunda meydana gelen kalıntı gerilmelerin neden olduğu tespit edilmiştir. En düşük majör BŞD'nin minör BŞD değerinin, 1sıl işlem ve süzdürme çubuğu ile bastırmanın etkisi ile, sırasıyla yaklaşık 0,01 ve 0,013 BŞD ve bu iki etki birlikte incelendiğinde ise 0,022 BŞD sola ötelendiği görülmüştür. Bu durumda toplamdaki 0,040 BŞD sağa ötelenme miktarının 0,023 BŞD’lik kısmının ısıl işlem ve süzdürme çubuğuyla bastırma sebebiyle oluştuğu tespit edilmiştir.

Tablo 4. Eğrilikten kaynaklanan olası ötelenme değerleri (Possible offsetting values from the bending effect)

\begin{tabular}{|c|c|c|c|c|c|}
\hline Kalınlık & & İç yüzey & Dış yüzey & $\begin{array}{c}\text { Ölçülen } \\
\text { ötelenme }\end{array}$ & $\begin{array}{c}\text { Teorik } \\
\text { ötelenme }\end{array}$ \\
\hline \multirow{2}{*}{$0,8 \mathrm{~mm}$} & Sınır majör BŞD & 0,1390 & 0,1479 & $0-0,0089$ & \multirow{2}{*}{$0-0,008$} \\
\hline & Sınır minör BŞD & 0,0320 & 0,0390 & $0-0,0070$ & \\
\hline \multirow{2}{*}{$2 \mathrm{~mm}$} & Sınır majör BȘD & 0,1698 & 0,1850 & $0-0,0152$ & \multirow{2}{*}{$0-0,02$} \\
\hline & Sınır minör BŞD & 0,0330 & 0,0440 & $0-0,0110$ & \\
\hline
\end{tabular}

Tablo 5. O temperi durumundaki numunenin iç ve dış yüzeyinden deneysel belirlenen sınır BŞD’ler (Obtained limit strains from the inner and outer surfaces of the specimen for $\mathrm{O}$ temper)

Al 2024-O

\begin{tabular}{|c|c|c|c|} 
& İç yüzey & Dış yüzey & BŞD fark1 \\
\hline Majör & 0,1575 & 0,1650 & 0,0075 \\
\hline Minör & 0,0070 & 0,0140 & 0,0070 \\
\hline
\end{tabular}


- BŞD'ler numunelerin iç ve diş yüzeylerinden ölçülerek eğilme etkisiyle, kalınlığa göre 0,007 0,011 minör BŞD aralığında ötelenmenin de olabileceği ortaya konulmuştur.

- Ölçümlerde yapılan hatalar ve ŞSE'lerin elde edilmesindeki 0,013 belirsizlik değeri göz önüne alındığında, 0,04 BŞD ötelenme değeri büyük kabul edilebilir.

\section{SEMBOLLER (NOMENCLATURE)}

$t \quad$ Sac kalınlığı $(\mathrm{mm})$

$r \quad$ Stampa yarıçapı $(\mathrm{mm})$

$d \quad$ Stampa çapı $(\mathrm{mm})$

$\sigma_{a} \quad$ Akma mukavemeti (MPa)

$\sigma_{u} \quad$ Çekme mukavemeti $(M P a)$

$\varepsilon_{g} \quad$ Toplam gerçek uzama

n Pekleşme katsayısı

$K \quad$ Mukavemet katsayısı $(M P a)$

\section{TEŞEKKÜR (ACKNOWLEDGEMENT)}

$\mathrm{Bu}$ çalışma Murat Dilmeç'in doktora tez çalışmasından çıkartılmıştır. Yazarlar, Necmettin Erbakan ve Selçuk Üniversiteleri Bilimsel Araştırma Projeleri Koordinatörlüklerine, çalışmanın bir kısmını içeren 108M516 numaralı projesi kapsamında alınan destekler için TÜBİTAK'a, ŞSE testlerinin bir kısmının gerçekleştirildiği Niğde Üniversitesi Metal Şekillendirme Laboratuvarı ve Atılım Üniversitesi Metal Şekillendirme Mükemmeliyet Merkezine teşekkürü bir borç bilir.

\section{KAYNAKLAR (REFERENCES)}

1. Emilie, H., Carsley, J.E., Verma, R. "Development of Forming Limit Diagrams of Aluminum and Magnesium Sheet Alloys at Elevated Temperatures", Journal of Materials Engineering and Performance, 17 (3), 288-296, 2008.

2. Karaağaç İ., Özdemir A., "Erdemir 6112 Sac Malzemenin Hidromekanik Derin Çekme Yöntemiyle Şekillendirilebilirliği”, Journal of The Faculty of Engineering and Architecture of Gazi University, Cilt 26, No 4, 841-850, 2011.

3. Paraianu, L., Comşa, D.S., Gracio, J.J., Banabic, D., "Modelling of the Forming Limit Diagrams Using the Finite Element Method", The 8th International Conference of the European Scientific Association for Material Forming ESAFORM 2005.

4. Keeler, S.P. and Backofen, W.A., "Plastic Instability and Fracture in Sheets Stretched Over Rigid Punches", ASM Trans. Quart., 56, 25-48, 1963.
5. Narayanasamy, R., Narayanan, S.C., "Experimental Analysis and Evaluation of Forming Limit Diagram for Interstitial Free Steels", Materials and Design, 28, 1490-1512, 2007.

6. Casari, F., Tassan M., Messina A., Molinari A., "Effect of Punch Diameter, Grid Dimension and Lubrication on Forming Limit Diagram", Journal of Testing and Evaluations, 34 (1), 24-30, 2006.

7. Raghavan, K.S., "A Simple Technique to Generate In-Plane Forming Limit Curves and Selected Applications", Metallurgical and Materials Transactions A, 26A, 2075-2084,1995.

8. Djavanroodi, F., Derogar, A., "Experimental and numerical evaluation of forming limit diagram for Ti6Al4V titanium and Al6061-T6 aluminum alloys sheets", Materials and Design, 31, 48664875, 2010.

9. George, E.T., MacKenzie DS. Handbook of Aluminum, Physical Metallurgy and Processes. New York: Marcel Dekker Inc., 2003.

10. US Army Materials and Mechanics Research Center, Military Standardization Handbook, Aluminum and Aluminum Alloys, 1966.

11. Dilmec, M., Halkaci, H.S., Ozturk, F., Turkoz, M. "Detailed investigation of forming limit determination standards for aluminum alloys", Journal of Testing and Evaluation, 41(1): 10-21, 2012.

12. Ameen H.A., Effect of spring stiffness and coefficient of friction on the stresses distribution and die angle in extrusion process, Am. J. Sci. Ind. Res., 1 (2), 164-179, 2010.

13. Ozturk F., Dilmec M., Turkoz M., Ece R.E., Halkaci H.S., "Grid Marking and Measurement Methods for Sheet Metal Formability". The 5th International Conference and Exhibition on Design and Production of Machines and Dies/Molds, Turkey, June 18-21, 41-49, 2009.

14. Dilmeç, M., "2024-T4 Alüminyum Sacların Şekillendirme Sınır Eğrilerinin Kalınlığa Göre Değişimi”, Doktora Tezi, Selçuk Üniversitesi, Fen Bilimleri Enstitüsü, 2012.

15. Dilmec M., Halkaci H.S., Ozturk F., Livatyali H., Yigit O. "Effects of sheet thickness and anisotropy on forming limit curves of AA2024-T4", International Journal of Advanced Manufacturing Technology 67 (9), 2689-2700, 2013.

16. Laukonis, J.V. and Ghosh, A.K., "Effects of Strain Path Changes on the Formability of Sheet Metals", Metallurgical Transactions A, 9A, 1849-1856, 1978.

17. Hosford, W.F. and Caddell, R.M., "Mechanics and Metallurgy", 2nd Edition, Prentice Hall Inc., USA, 1993 